\title{
Bioaerossóis em ambientes hospitalares
}

\author{
Marina Dantas Vanetti ${ }^{1}$, Camilla Dal Col Oliveira ${ }^{1}$, Bruno Consul de Almeida ${ }^{2}$, Maria Cristina Dantas Vanetti ${ }^{3}$ \\ 1. Estudante do Curso de Graduação em Medicina, Centro de Ciências da Saúde, Universidade Federal de Santa Catarina \\ (UFSC), Campus Reitor João David Ferreira Lima. Florianópolis, Santa Catarina, Brasil. \\ 2. Estudante do Curso de Graduação em Medicina, Universidade Milton Lins. Manaus, Amazonas, Brasil. \\ 3. Professora do Departamento de Microbiologia, Universidade Federal de Viçosa. Viçosa, Minas Gerais, Brasil.
}

\begin{abstract}
RESUMO
Bioaerossol se refere aos aerossóis biológicos dispersos na atmosfera formados de partículas bióticas ou abióticas de ecossistemas terrestres e marinhos. A composição da microbiota dos bioaerossóis é variável, dinâmica e relativa às origens de seus componentes, bem como à temperatura e à umidade do meio no qual estão suspensas. Este artigo revisa sistematicamente a literatura relacionada ao potencial epidemiológico dispersivo de bioaerossóis no ambiente hospitalar. Os bioaerossóis, assim como as gotículas, constituem importantes meios de transmissão de patógenos e o impacto dessas partículas em ambientes hospitalares é de importância, por estarem associadas à diversas doenças nosocomiais. O novo coronavírus possui alto poder de contágio e utiliza a rota aérea como uma das vias para transmissão, o que evidencia a importância de garantia da qualidade do ar em ambientes hospitalares no momento em que uma pandemia mundial está em curso.
\end{abstract}

DOI: https://doi.org/10.32963/bcmufsc.v6i2.4346 Indexadores: Aerossóis; COVID-19; Infecções nosocomiais; Patógenos; Qualidade do ar interno Submetido em 15/09/2020; aceito para publicação em 18/10/2020. Os autores declaram não possuir conflito de interesse.

Autor para contato: Prof ${ }^{\underline{a}}$ Maria Cristina Dantas Vanetti. E-mail: mvanetti@ufv.br

\section{Introdução}

Bioaerossóis são constituídos por partículas e organismos vivos ou substâncias por eles produzidas, suspensos na atmosfera e exibem grande diversidade. Sua composição e concentração variam de acordo a natureza do material disperso no ar e com fatores ambientais. No ar de ambientes internos, os bioaerossóis podem constituir frações de 5 a $34 \%$ da poluição' e possuem impacto direto na saúde humana dependendo do tipo e do número de microrganismos. Os bioaerossóis têm sido estudados para determinar as fontes de contaminação de doenças epidêmicas, pois sua inalação está relacionada a doenças infecciosas, alergias, câncer e intoxicações agudas, o que os faz uma possível arma para o bioterrorismo.

As partículas que compõem os aerossóis podem se depositar em diferentes partes do sistema respiratório. Em ambientes fechados, como em hospitais, a carga microbiana dessas partículas é influenciada pelo número de ocupantes, natureza, grau da atividade exercida, ventilação e outros fatores ambientais. Apesar dos muitos efeitos adversos à saúde resultantes da exposição humana aos bioaerossóis, o impacto destas partículas na saúde pública ainda não está totalmente compreendido.
O cenário atual da síndrome respiratória aguda grave e pandêmica causada pelo novo Coronavírus (SARS-CoV-2) e as evidências da sua transmissão pelo ar, por meio de gotículas de saliva, espirro, tosse e secreções e pelo contato direto entre pessoas, reforça a importância do estudo e monitoramento dos bioaerossóis como uma possível e importante forma de transmissão de doenças. A rápida disseminação do vírus, com grande número de casos e mortes em diferentes países, gera questionamentos, especialmente sobre a permanência das partículas virais no ambiente, potencializando a poder de transmissão desse patógeno. A manutenção de ambientes bem ventilados, uso de máscaras, distanciamento social e a higiene com sabão e álcool 70\% visam minimizar a contaminação pelo novo vírus e possuem relação direta com a menor exposição a esses aerodispersóides contaminados.

Estima-se que, apenas em 2016, a poluição do ar interior e exterior tenha causado cerca de 7 milhões de mortes no mundo ${ }^{3}$. A necessidade de se repensar a contenção de doenças respiratórias frente à pandemia da COVID-19 e às dinâmicas de emissão de partículas poluentes justifica esta revisão. Portanto, este trabalho objetivou analisar a presença e a composição dos bioaerossóis em ambientes hospitalares e como esses fatores impactam na saúde humana. 


\section{Método}

Foi feita uma revisão sistemática de artigos sobre bioaerossóis, principalmente no âmbito hospitalar, nos últimos 20 anos. A busca bibliográfica foi realizada de março a julho de 2020, nas bases de dados do portal da Capes, da Biblioteca Virtual em Saúde (LILACS, MEDLINE, SciELO, Cochrane Library), OVID e Embase, nos idiomas português e inglês e abrangeu artigos publicados entre janeiro de 2000 a julho de 2020. Foram utilizados os operadores booleanos AND, OR e NOT, cruzando-se os descritores anteriormente relacionados nas bases de dados citadas. No estudo foram incluídos artigos originais, revisões bibliográficas e estudos de caso que incluíssem o tema bioaerossóis, principalmente em contexto hospitalar.

\section{Revisão}

\section{Bioaerossóis e sua presença em ambientes hospitalares}

Considera-se que os bioaerossóis são partículas suspensas na atmosfera originárias de fontes biológicas naturais ou antrópicas e que podem conter fungos e bactérias, vivos ou mortos, vírus, endotoxinas bacterianas, micotoxinas, peptideoglicanos, $\beta(1,3)$ glicanos, alergênicos de alto peso molecular, pólens, poeira e outros resíduos metabólicos. Portanto, a exposição de seres humanos a essas partículas pode contribuir para a ocorrência de muitas doenças. O termo gotículas também é usado para definir partículas presentes no ar e, segundo a Organização Mundial da Saúde $(\mathrm{OMS})^{5}$ e a ANVISA $^{6}$ gotículas geralmente são consideradas partículas maiores do que $5 \mu \mathrm{m}$ de diâmetro e os aerossóis, partículas de tamanho inferior à $5 \mu \mathrm{m}$. As gotículas são produzidas durante a fala, espirro ou tosse, expelidas como uma nuvem de partículas e resultam na exposição potencial de pessoas suscetíveis que estejam a menos de um metro da pessoa fonte (Figura 1). Por outro lado, os bioaerossóis podem permanecer no ar por longos períodos de tempo e serem transmitidos a outras pessoas a distâncias curtas ou superiores a $1 \mathrm{~m}$ (Figura 1).

Os bioaerossóis contendo agentes infecciosos são considerados uma via potencial de transmissão de patógenos causadores de infecções nosocomiais. O ambiente hospitalar pode ser contaminado por diferentes fontes, mas considera-se que os seres humanos sejam a origem primária de certas bactérias e vírus para o ambiente ${ }^{7.8}$. Além do trato respiratório, pele e cabelo humanos são fonte potencial de microrganismos patogênicos presentes em bioaerossóis ${ }^{9}$ e, mesmo que não sejam a fonte primária de fungos, as atividades desenvolvidas por humanos são importantes para a contaminação dos aerodispersíveis por materiais de origem fúngica ${ }^{7}$. Assim, indivíduos doentes no ambiente hospitalar podem produzir bioaerossóis com patógenos enquanto indivíduos saudáveis podem se contaminar ao inalá-los.

Dentre as bactérias comumente encontradas no ar hospitalar destacam-se espécies de Staphylococcus, Streptococcus e Escherichia ${ }^{10}$. Pseudomonas aeruginosa, Acinetobacter baumannï e Staphylococcus schleiferi foram isolados em nove dos 10 ambientes internos de um hospital enquanto Staphylococcus aureus foi detectado em 50\% desses ambientes". Há evidências da transmissão aérea de $S$. aureus resistente à meticilina (MRSA), Acinetobacter spp. e Pseudomonas spp. em surtos nosocomiais ${ }^{1}$. Foi identificado que $75 \%$ das bactérias isoladas do ar hospitalar pertenciam aos gêneros Staphylococcus e Micrococcus, o que reforça a importância destes patógenos em bioaerossóis ${ }^{12}$. A detecção de bactérias como Escherichia coli multirresistentes a antibióticos no ar de ambientes hospitalares é outra preocupação que representa ameaça potencial à saúde de pacientes, profissionais de saúde e residentes na vizinhança ${ }^{13}$. Actinomicetos como Streptomyces e algas causam alergia, reações inflamatórias e pneumonite por hipersensibilidade $^{1}$ e são passíveis de transporte pelos bioaerossóis.

A inalação de fungos em bioaerossóis pode resultar em doenças do trato respiratório superior e inferior, como alergia e asma. Crianças e indivíduos imunocomprometidos de todas as idades são particularmente mais susceptíveis ${ }^{14}$. Os fungos frequentemente encontrados em bioaerossóis em ambientes hospitalares são Aspergillus spp., Cladosporium spp. e Penicillium spp..$^{10,12}$, além de Paecilomyces spp.'. . A presença desses fungos é usada como indicador de qualidade do ar em interiores ${ }^{15} \mathrm{e}$, juntamente com outros fungos transmitidos pelos aerossóis, como Acremonium e Mucor, são causadores de reações alérgicas e infecções respiratórias'.

Existem também protozoários aerosólicos que causam doenças respiratórias e meningoencefalite tais como Acanthamoeba e Naegleria fowleri. Os efeitos dos protozoários nas vias respiratórias resultam em doenças raras associadas, na maioria dos casos, a uma situação clínica subjacente correspondente a estados de supressão da imunidade, como em pacientes portadores do vírus da AIDS, transplantados, com hemopatias malignas, corticoterapia, entre outros 16 .

As infecções virais são de disseminação frequente em ambientes internos devido à facilidade de 
transmissão do patógeno em locais com alto número de ocupantes e com má ventilação ${ }^{17}$. Dentre as infecções causadas por vírus e que possuem o ar como importante forma de transmissão, pode-se destacar a síndrome respiratória aguda grave $(\mathrm{SARS})^{18}$, vírus entéricos presentes no esgoto, hantavírus, vírus provenientes de fezes de roedores ${ }^{19}$, varicela, sarampo, catapora e rubéola ${ }^{1}$, coronavírus, rinovírus, influenza, adenovírus e vírus sincicial respiratório $(\mathrm{VSR})^{17}$.

$\mathrm{O}$ transporte e a deposição de bioaerossóis dependem de suas propriedades físicas como densidade, tamanho e formato das partículas e das condições ambientais em que essas se encontram, incluindo magnitude de correntes de ar, umidade relativa e temperatura ${ }^{1}$.

Segundo a ANVISA ${ }^{6}$, as gotículas respiratórias, expelidas durante tosses, falas e espirros e constituídas por partículas maiores que $5 \mu \mathrm{m}$ de diâmetro, permanecem pouco tempo suspensas no ar (Figura 1) e, quando inaladas, atingem principalmente a mucosa alta, cavidade nasal e oral. Além disso, são uma das principais vias de transmissão do SARS-CoV-2, $2^{5,20}$. Além de ser transmitido por gotículas, a contaminação pelo SARSCoV-2 possivelmente pode ocorrer por aerossóis gerados em procedimentos específicos, como em intubação ou aspiração traqueal, ventilação mecânica não invasiva, ressuscitação cardiopulmonar, ventilação manual antes da intubação, coletas de amostras nasotraqueais e broncoscopias realizados em pacientes portadores do vírus ${ }^{20}$. Em análises de 75.465 casos de COVID-19 na China, a transmissão pelo ar não foi relatada $^{21}$, no entanto, foi demonstrado que o novo coronavírus permaneceu com potencial virulento em bioaerossóis durante as 3 horas em que foi monitorado, embora com redução do número de partículas por mililitro de ar. Os autores concluíram que a transmissão do SARS-CoV-2 por aerossol é plausível, pois o vírus pode permanecer infeccioso em aerossóis por horas, dependendo do inóculo ${ }^{22}$. Embora a presença de RNA do novo vírus tenha sido detectada no ar de ambiente clínico, a extensão da transmissão das partículas pelo ar ainda não é conhecida ${ }^{23}$. $\mathrm{O}$ atual paradigma da transmissão do SARS-CoV-2 pelo ar está na limitação chave das definições de transmissão de partícula aerotransportadas e decorre da dicotomia existente em relação ao tamanho das partículas e distância por elas percorrida. Pequenas partículas definidas como bioaerossóis, são inaladas por uma pessoa suscetível a alguma distância da fonte, caracterizando uma transmissão aérea, enquanto gotículas se projetam na mucosa facial de um indivíduo próxima à fonte ${ }^{24}$.

As máscaras constituem barreira física eficaz para reter partículas de tamanhos superiores a $20 \mu \mathrm{m}^{25} \mathrm{e}$ podem bloquear gotículas ejetadas pelo usuário. Portanto, ao serem utilizadas por indivíduos contaminados, diminuem a transmissão do agente etiológico. As evidências sugerem que a adoção quase universal de máscaras não médicas em público, em combinação com medidas complementares de saúde pública, reduz a transmissão de influenza e mostraramse eficazes em ensaios para bloquear a transmissão comunitária do coronavírus ${ }^{26}$.

A Sociedade de Doenças Infecciosas da América (IDSA) ${ }^{27}$ propôs uma classificação, nomeando de "partículas respiráveis" aquelas com diâmetro menor ou igual a $10 \mu \mathrm{m}$ que ao serem inaladas penetram na região alveolar; enquanto as "partículas inspiráveis" apresentam diâmetro entre $10 \mu \mathrm{m}$ e $100 \mu \mathrm{m}$ e, quando inaladas, não penetram na região alveolar, mas podem depositar na região das vias aéreas superiores.

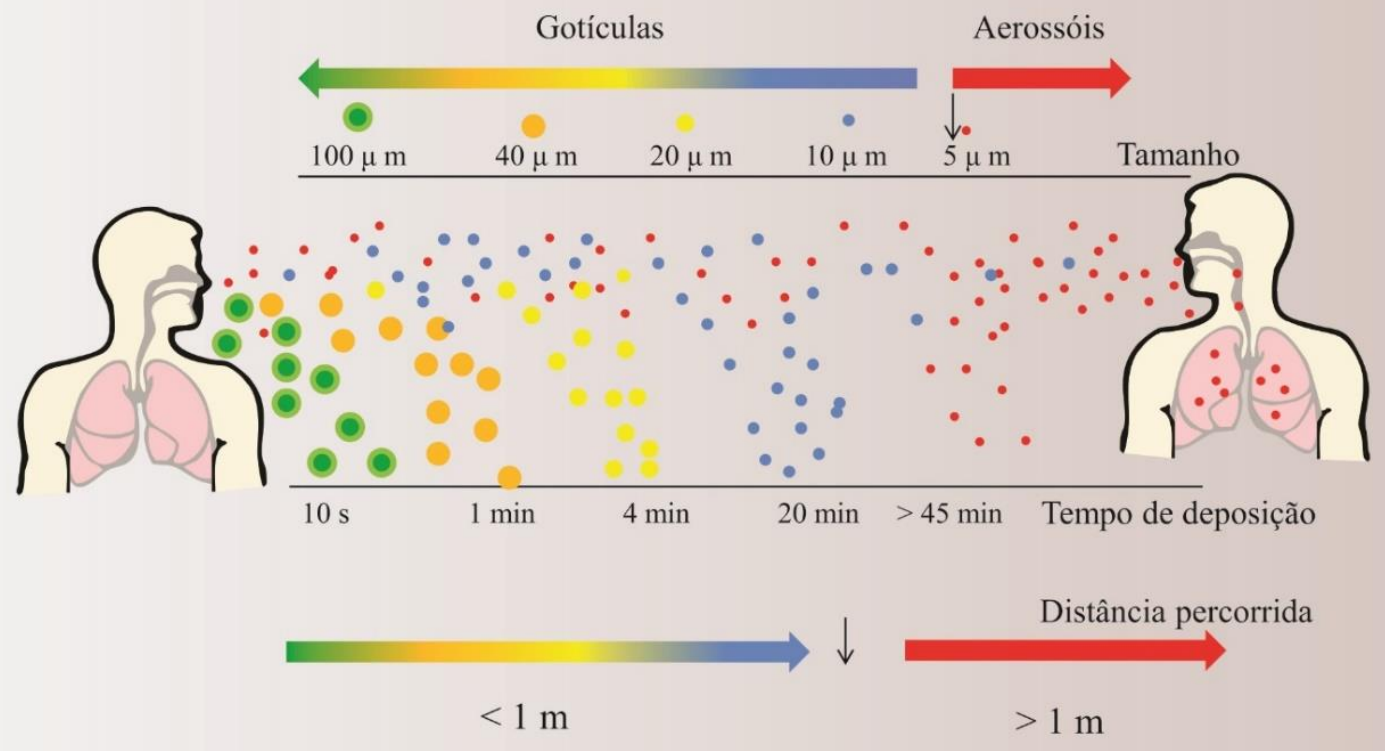

Figura 1. Esquema representativo da emissão e dispersão de gotículas e aerossóis formados durante fala, respiração, tosse ou espirro. 
A ventilação de ambientes, em geral, reduz a carga microbiana por causar efeito de diluição do $\operatorname{ar}^{1}$ enquanto a ventilação artificial, com manutenção inadequada, pode resultar em efeito contrário, aumentando a concentração de microrganismos no ambiente $^{10}$. Os bioaerossóis provenientes dos sistemas de refrigeração das salas hospitalares, ao passarem pelos filtros dos aparelhos, ficam retidos junto com a umidade. Essa combinação favorece a proliferação microbiana e a formação de biofilmes sobre $o$ filtro ${ }^{29}$ que vão constituir fonte contínua de contaminação. Além disso, em hospitais, há baixa renovação do ar, que é reciclado em cerca de 90\% devido ao constante uso de condicionadores de ar, aliado à retenção de microrganismos em filtros, provoca aumento do número de partículas virais em até 100.000 vezes $^{30}$. Segundo Silva et al. ${ }^{8}$, surtos de infecção hospitalar estão associadas à filtros de refrigeradores contaminados por bioaerossóis. A presença do novo coronavírus em amostras coletadas por swabs em sistemas de ventilação em um hospital em Singapura reforça o potencial de contaminação do ar ambiente por estes aparelhos ${ }^{31}$. Além disso, outros equipamentos utilizados no ambiente hospitalar também podem ser fontes de patógenos, dentre eles, destacam-se nebulizadores e umidificadores ${ }^{8}$. Superfícies como pias, drenos, lavatórios apresentam potencial para crescimento bacteriano e podem ser contaminadas pela deposição de bioaerossóis e contribuem para a contaminação ambiente.

\section{Formas de contágio por bioaerossóis}

Dentre as diferentes formas de aquisição de patógenos por meio de bioaerossóis destacam-se a ingestão, o contato com a pele e a inalação, sendo essa última, considerada o principal meio de contaminação'. Vírus como os causadores de $\mathrm{SARS}^{18}$, vírus entéricos presentes no esgoto, vírus sincicial respiratório (VSR), hantavírus provenientes de fezes de roedores ${ }^{19}$, varicela, sarampo, catapora e rubéola utilizam o aerossol como principal rota de contágio.

Entre os procedimentos realizados em hospitais, a intubação endotraqueal gera partículas de aerossol $^{20}$, o que aumenta a carga microbiana no ambiente e facilita a transmissão de patógenos, principalmente para pessoas que estão próximas ao paciente. No cenário da pandemia decorrente do novo coronavírus é ainda mais importante dar atenção a esse processo, uma vez que há evidências de que esse vírus pode ser transmitido por bioaerossóis, apesar de esta não ser considerada a principal via. Segundo a OMS $^{5}$, o contato com gotículas respiratórias constitui a via mais frequente de contágio pelo novo coronavírus.
Com o objetivo de minimizar a contaminação do ar pelo vírus, o Ministério da Saúde recomenda que o processo de intubação seja realizado pelo profissional mais experiente e treinado presente no local ${ }^{20}$. Deve-se também priorizar a intubação em sequência rápida sempre que possível e, quando necessária a préoxigenação, essa deve ser realizada com máscara facial com bolsa reservatório ${ }^{20}$. Considerando a elevada transmissibilidade do vírus, a frequente necessidade de intubação em pacientes graves acometidos pela COVID$19^{32}$ e a alta taxa de mortalidade causada por esse patógeno em pacientes pertencentes ao grupo de risco, faz-se ainda mais urgente a necessidade de controle da qualidade do ar em ambientes hospitalares.

Os patógenos aerodispersíveis podem ser classificados como obrigatoriamente transmissíveis pelo ar, que são aqueles que dependem exclusivamente dos aerossóis como meio de transmissão, como a tuberculose ${ }^{33}$. Há também patógenos preferencialmente transmissíveis pelo ar, que apesar de utilizarem os aerossóis como principal via de contaminação, podem iniciar uma infecção por meio de outras rotas, como o contato direto. Neste grupo podem ser incluídos vírus que causam exantemas. Por último, observa-se a existência de patógenos oportunistas transmissíveis pelo ar, que naturalmente causam infecções e são veiculados por outros meios, porém podem infectar pulmões e propagar-se por partículas aerossólicas.

\section{hospitalar}

Importância dos aerossóis em ambiente

Microrganismos patogênicos presentes em partículas aerodispersíveis representam ameaça para a saúde da população hospitalar e, por mais que essa forma de contágio não seja a principal causadora de infecções nosocomiais, esse meio de aquisição precisa ser considerado. Dentre os efeitos adversos da presença de patógenos em bioaerossóis em hospitais, a infecção hospitalar é o mais expressivo, uma vez que gera óbitos nos serviços de saúde em todo o mundo.

O risco apresentado pelos patógenos presentes no ar varia de acordo com a concentração, estado de saúde do hospedeiro e tempo de exposição ${ }^{1}$. Assim, a qualidade do ar em recintos onde os pacientes permanecem em maior tempo de exposição, como UTIs, tem efeito coadjuvante na recuperação do indivíduo. Além desses locais de cuidados intensivos, centros cirúrgicos também apresentam importantes riscos na contaminação do paciente, uma vez que a barreira principal de proteção do organismo é rompida, facilitando a entrada do patógeno no organismo humano. Em razão do considerável impacto que 
bactérias transmitidas pelo ar possuem nas infecções causadas durante cirurgias', a atenção a ser dada ao tipo de ventilação desses ambientes e sua manutenção nos sítios cirúrgicos devem ser mais criteriosas. Afonso et al. ${ }^{29}$ concluíram que o controle da qualidade do ar nos sítios de operação é essencial para reduzir o risco de contaminação dos pacientes, o que reforça o potencial contaminante dos filtros de climatizadores e a necessidade de mantê-los limpos. Segundo a legislação brasileira em vigor ${ }^{2}$, que trata da contaminação de ambientes fechados públicos e coletivos climatizados, o Valor Máximo Recomendável é de 750 UFC de fungos $/ \mathrm{m}^{3}$. Embora não haja um padrão específico para ambientes hospitalares, os limites desta Resolução têm sido discutidos. Quadros et al. ${ }^{15}$ registraram valores que variaram entre 62 a $591 \mathrm{UFC} / \mathrm{m}^{3}$ de fungos em ambientes hospitalares, como UTIs e centros cirúrgicos e Vargas et al. ${ }^{34}$ encontraram 23 UFC de fungos por placa de Petri exposta ao ar por uma hora em uma sala de radiologia. Estes resultados, entre outros, sugerem que essa Resolução apresenta baixo rigor, uma vez esse valor não foi atingido nessas pesquisas. Além disso, a Resolução não contempla limites de contaminação por bactérias que possuem relevância para a saúde. Uma legislação específica para ambientes hospitalares deveria levar em consideração as características do público que o hospital atende, como imunodeprimidos e com morbidades, por possuírem maiores riscos de desenvolvimento de doenças nosocomiais. Outro fator a se considerar é o risco que diferentes ambientes hospitalares podem oferecer ao paciente. Segundo Norma da ABNT 7.256/2005 $5^{35}$ os ambientes são classificados de acordo com o risco à saúde e portanto, o limite máximo de microrganismos deveria depender da classificação do nível de risco associados à qualidade do ar.

Outro ponto também questionável se refere à relação $\mathrm{I} / \mathrm{E}$, sendo I a concentração em $\mathrm{UFC} / \mathrm{m}^{3}$ interna e $\mathrm{E}$ a concentração em $\mathrm{UFC} / \mathrm{m}^{3}$ externa que, de acordo com a mesma Resolução, tem como limite superior o valor de 1,5. Esse valor significa que a concentração de microrganismos em ambientes internos pode ser maior que as concentrações externas. No entanto, os ambientes externos são considerados os detentores das maiores concentrações de microrganismos no ar, assim valores maiores que 1 indicam que há fontes de microrganismos contaminantes dentro do estabelecimento ${ }^{15}$.

A análise e o monitoramento dos bioaerossóis dentro de um hospital são importantes para o acompanhamento de doenças, para controle de infecções nosocomiais e para identificarem fontes e formas de dispersão desse material, além de informar sobre a necessidade de procedimentos para reduzir a contaminação. De acordo com Wutke ${ }^{36}$, a empresa Lusa DECO PROTESTE analisou parâmetros relacionados à quantidade de bactérias, fungos e leveduras a partir de amostras de ar coletadas em enfermarias, corredores, urgências e salas de espera, de 19 hospitais públicos e privados das cidades de Coimbra e Lisboa, em Portugal. Mais da metade daqueles locais apresentou resultados acima dos recomendados pela OMS. Afonso et al. ${ }^{29}$ realizaram uma revisão bibliográfica no período de 1990 a 2001 sobre o risco de infecções hospitalares por Aspergillus, Legionella, Acinetobacter, Clostridium e Nocardia no Brasil e concluíram que a presença desses patógenos está relacionada às péssimas condições de limpeza e manutenção adequada dos aparelhos de ar condicionado, comprometendo a qualidade do ar em ambientes hospitalares climatizados.

\section{Conclusões}

Embora bioaerossóis e gotículas sejam conceitualmente diferentes em relação ao tamanho das partículas, ambos constituem importantes veículos de propagação de microrganismos. A análise do ar dos ambientes hospitalares e a devida manutenção de equipamentos devem respeitar as normas estabelecidas visando interromper a cadeia de transmissão de patógenos, principalmente em ambientes onde estão presentes pessoas mais susceptíveis ao desenvolvimento de doenças. Para um maior controle da qualidade interna do ar dos hospitais, cabe uma atenção especial da ANVISA para criar uma legislação específica para hospitais, incluindo bactérias como parâmetro de qualidade do ar e a adoção de um limiar mais rigoroso de UFC, que compreenda a susceptibilidade dos pacientes e profissionais.

Os dados da contaminação do ar por vírus em ambientes hospitalares são escassos, a metodologia não é padronizada e não há parâmetros legais propostos. $\mathrm{O}$ presente cenário mundial, com a pandemia causada pelo novo coronavírus, demonstra a importância do desenvolvimento de estudos nesta área.

\section{Agradecimentos}

Os autores agradecem a Deisy Guimarães Carneiro pelo auxílio na formatação final da figura. 


\section{Referências}

1. Srikanth P, Sudharsanam S, Steinberg R. Bioaerosols in indoor environment: composition, health effects and analysis. Indian Journal of Medical Microbiology 2008; 26(4): 302-12.

2. Brasil. Resolução Resolução no 9 , de 16 de Janeiro de 2003. Orientação Técnica elaborada por Grupo Técnico Assessor, sobre Padrões Referenciais de Qualidade do Ar Interior, em ambientes climatizados artificialmente de uso público e coletivo. Diário Oficial da União 2003; 20 jan. Agência Nacional de Vigilância Sanitária - ANVISA.

3.Organização Mundial da Saúde (OMS). Mortality from household and ambient air pollution. 2018.

https://www.who.int/gho/phe/air_pollution_mortality/en / (acessado em 2020 Jul 4)

4.Ghosh B, Lal H, Srivastava A. Review of bioaerosols in indoor environment with special reference to sampling, analysis and control mechanisms. Environmental International 2015; 85:254-272. doi: 10.1016/j.envint.2015.09.018.

5.Organização Mundial da Saúde (OMS). Infection prevention and control of epidemic- and pandemic-prone acute respiratory infections in health care. Geneva: World Health Organization; 2014 https://apps.who.int/iris/bitstream/handle/10665/112656 /9789241507134_eng.pdf? sequence=1

6.Agência Nacional de Vigilância Sanitária (ANVISA). Cartilha de proteção respiratória contra agentes biológicos para trabalhadores de saúde. http:/www2.ebserh.gov.br/documents/214604/816023/ Cartilha + de + Prote $\%$ C3\%A7\%C3\%A30+Respirat\%C3\% B3ria + contra + Agentes + Biol\%C $3 \%$ B3gicos + para + Trabal hadores+de+Sa\%C3\%BAde.pdf/58075f57-eee2-4ec5aa96-743d142642f1 (acessado: 02/07/2020)

7. Nazaroff W. Indoor bioaerosol dynamics. Indoor Air 2014; 26:61-78. doi:10.1111/ina.12174

8. Silva DPS, Nazaré DL, Muniz JWC, Câmara CNS. Infecções hospitalares associadas à qualidade do ar em ambientes climatizados. Revista de Epidemiologia e Controle de Infecção 2013; 3(4):153-157.

9.Li CS, Hou PA. Bioaerosol characteristics in hospital clean rooms. The Science of the Total Environment 2003; 305:169-176.

10.Stockwell RE, Ballard EL, O'Rourke P, Knibbs LD, Morawska L, Bell SC. Indoor hospital air and the impact of ventilation on bioaerosols: a systematic review. Journal of Hospital Infection 2019; 103:175-184. doi.org/10.1016/j.jhin.2019.06.016

11. Pereira RG, Reis D, Ambrósio Júnior GN, Raddi, MSG, Pedigone MAM, Martins CHG. Bioaerossóis bacterianos em um hospital. Revista de Bol Curso Med UFSC 2020; 6 (2)
Ciências Farmacêuticas Básica e Aplicada 2005; 26(1):77-81.

12. Mirhoseini SH, Didehdar M, Akbari M, Moradzadeh R, Jamshidi R, Torabi S. Indoor exposure to airborne bacteria and fungi in sensitive wards of an academic pediatric hospital. Aerobiologia 2020; 36:225232. doi.org/10.1007/s10453-020-09624-0.

13. Wu B, Qi C, Wang L, Yang W, Zhou D, Wang M, Dong Y, Weng H, Li C, Hou X, Long X, Wang $\mathrm{H}$, Chai T. Detection of microbial aerosols in hospital wards and molecular identification and dissemination of drug resistance of Escherichia coli. Environment International 2020; 137:1-10. doi.org/10.1016/j.envint.2020.105479.

14. Foarde KK, Dean T, Betancourt D, Kim J, Devine A, Byfield G, Menetrez M. Molds and mycotoxins: factors that affect exposure and contribute to adverse health effects. In: Johanning, E.; Morey, P.; Auger, P. (eds): Bioaerosols - Fungi, Bacteria, Mycotoxins in Indoor and Outdoor Environments and Human Health. WHO, 2013.

15. Quadros ME, Lisboa HM, Oliveira VL, Schirmer WN. Qualidade do ar em ambientes internos hospitalares: estudo de caso e análise crítica dos padrões atuais. Engenharia Sanitária Ambiental 2009; 14(3):431438.

16. Martınez-Giro R, Esteban JG, Ribas A, Doganci L. Protozoa in respiratory pathology: a review. European Respiratory Journal 2008; 32:1354-1370. doi: 10.1183/09031936.00022008.

17. La Rosa G, Fratini M, Libera SD, Iaconelli M, Muscillo M. Viral infections acquired indoors through airborne, droplet or contact transmission. Annali dell'Istituto Superiore di Sanità 2013 49(2):124132. doi: 10.4415/ANN_13_02_03.

18. Yu ITS, Li Y, Wong TW, Tam W, Chan AT, Lee JHW. Evidence of airborne transmission of the severe acute respiratory syndrome virus. England Journal of Medicine 2004; 350:1731-1739.

19. Figueiredo LTM, Campos GM, Rodrigues FB. Síndrome pulmonar e cardiovascular por Hantavirus: aspectos epidemiológicos, clínicos, do diagnóstico laboratorial e do tratamento, Revista da Sociedade Brasileira de Medicina Tropical 2001; 34(1):13-23.

20. Brasil. Ministério da Saúde. Secretaria de Atenção Especializada à Saúde. Departamento de Atenção Hospitalar, Domiciliar e de Urgência. Protocolo de manejo clínico da COVID-19 na Atenção Especializada [recurso eletrônico]/Ministério da Saúde, Secretaria de Atenção Especializada à Saúde, Departamento de Atenção Hospitalar, Domiciliar e de Urgência. - 1. ed. rev. - Brasília : Ministério da Saúde, 2020. 48 p. 
21. World Health Organization (WHO). Report of the WHO-China Joint Mission on Coronavirus Disease 2019 (COVID-19).16-24 February 2020 [Internet]. Geneva: World Health Organization; 2020 Available from: https:/www.who.int/docs/defaultsource/coronaviruse/who-china-joint-mission-on-covid19-final-report.pdf.

22. van Doremalen N, Bushmaker T, Morris DH, Holbrook MG, Gamble A, Williamson AB, Tamin, Harcourt JL, Thornburg J, Gerber S, LloydSmith JO, Wit M, VJ. Aerosol and surface stability of SARS-CoV-2 as compared with SARS-CoV-1. New England Journal of Medicine 2020; 382:1564-1567. doi: 10.1056/NEJMc2004973

23. Nardell EA, Nathavitharana R. Airborne spread of SARS-CoV-2 and a potential role for air disinfection. Journal of American Medical Association JAMA 2020; Published online June 1. doi:10.1001/jama.2020.7603.

24. Jones RM, Brosseau LM. Aerosol transmission of infectious disease. Journal of Occupational and Environmental Medicine 2015; 57(5):501-508.doi: 10.1097/JOM.0000000000000448

25. Tellier R, Li L, Cowling BJ, Tang JW. Recognition of aerosol transmission of infectious agents: a commentary. Infectious Diseases 2019; 19:101. doi.org/10.1186/s12879-019-3707-y

26. Shaikh FQ, Hernandez D, Chu LF, Ramirez CM, Rimoin AD, von Delft AP, Fridman F, Tang LH, Tang V, Watson GL, Bax CE, Howard J, Huang A, Li Z, Tufekc Z, Zdimal V, van der Westhuizen A. Face masks against COVID-19: An evidence. Review. Preprints (www.preprints.org) Posted: $12 \quad$ April 2020. doi:10.20944/preprints202004.0203.v1 reprints202004.0 203.v1

27. Institute of Medicine. Preventing transmission of pandemic and other viral respiratory diseases: personal protective equipment for healthcare personnel: Update 2010. Washington, DC: The National Academies Press. doi.org/10.17226/13027.

28.Guzman M. Bioaerosol size effect in COVID-19 transmission. Preprints (www.preprints.org),
Posted: 7 April

2020

doi:10.20944/preprints202004.0093.v1.

29. Afonso MSM, Tipple AFV, Souza ACS, Prado MA, Anders PS. A qualidade do ar em ambientes hospitalares climatizados e sua influência na ocorrência de infecções. Revista Eletrônica de Enfermagem 2004; 6 (2):181-188.

30. Lacerda RA. Centro cirúrgico. In: Fernandes ATF, Fernandes MO, Ribeiro Filho N. Infecção Hospitalar e suas Interfaces na Área da Saúde. São Paulo: Atheneu, 2000. p. 1307-1322.

31. Ong SWX, Tan YK, Chia PY, Lee TH, Ng OT, Wong MSY, Marimuthu K. Air, surface environmental, and personal protective equipment contamination by severe acute respiratory syndrome Coronavirus 2 (SARS-CoV-2) from a symptomatic patient. Journal of American Medical Association JAMA 2020; 323(16):1610-1612. doi: 10.1001/jama.2020.3227

32. Queiroz G. Coronavírus: sequência rápida ou sequência atrasada na intubação? Portal PebMed.[periódico na Internet]. 2020 Mar-Abr [acessado 2020 Jun 24]. Disponível em: https://pebmed.com.br/coronavirus-sequencia-rapidaou-sequencia-atrasada-na-intubacao/?login=modal .

33. Roy C, Milton D. Airborne transmission of communicable infection - The elusive pathway. The New England Journal of Medicine 2014; 350(17):1710-1712. doi:1710-2. 10.1056/NEJMp048051.

34. Vargas, KC, Gonzales KA. Avaliação da eficiência de sanitizantes em setores de radiologia em hospitais. Revista Agroambiental 2010; 2(1): 9-14.

35. ABNT - Associação Brasileira de Normas Técnicas NBR 7.256. Tratamento de ar em estabelecimentos assistenciais de saúde (EAS) Requisitos para projeto e execução das instalações. 2005. (Em revisão).

36. Wetke MCB. Desinfecção do ar em ambientes confinados pela ação combinada de dióxido de titânio e luz ultravioleta (TiO2/UV). [Dissertação]. Campinas, Faculdade de Engenharia Civil, Arquitetura e Urbanismo; 2006. 